\title{
Annales de Normandie, « La Révolution en Normandie. Nouvelles approches », dir. Michel Biard
}

\section{Samuel Guicheteau}

\section{(2) OpenEdition \\ 1 Journals \\ Édition électronique \\ URL : https://journals.openedition.org/ahrf/12077 \\ DOI : 10.4000/ahrf.12077 \\ ISSN : 1952-403X \\ Éditeur : \\ Armand Colin, Société des études robespierristes}

\section{Édition imprimée}

Date de publication : 1 juin 2011

Pagination : 269-270

ISSN : 0003-4436

\section{Référence électronique}

Samuel Guicheteau, «Annales de Normandie, «La Révolution en Normandie. Nouvelles approches », dir. Michel Biard », Annales historiques de la Révolution française [En ligne], 364 | avril-juin 2011, mis en ligne le 31 août 2011, consulté le 23 avril 2022. URL : http://journals.openedition.org/ahrf/12077 ; DOI : https://doi.org/10.4000/ahrf.12077

Ce document a été généré automatiquement le 23 avril 2022.

Tous droits réservés 


\title{
Annales de Normandie, « La Révolution en Normandie. Nouvelles approches ", dir. Michel Biard
}

\author{
Samuel Guicheteau
}

\section{RÉFÉRENCE}

Annales de Normandie, « La Révolution en Normandie. Nouvelles approches », Michel

Biard, dir., 2009-1, ISBN 978-2-902230-19-1, $20 €$

1 Ce numéro spécial des Annales de Normandie consacré à des travaux d'histoire régionale de la Révolution française, menés à l'Université de Rouen, est le premier volume de la nouvelle formule de la revue. Sa maquette est agréable.

2 Poursuivant l'étude de la dynastie des Le Couteulx, Richard Flamein présente ici un travail sur l'ensemble de bâtiments sis au 34 de la rue aux Ours, à Rouen, où voisinent le siège d'une entreprise aux activités variées et les demeures de certains membres de la famille. À chaque étape de l'ascension sociale des Le Couteulx (élite négociante, anoblissement, notabilité) correspondent non seulement des stratégies économiques, sociales et politiques, mais encore l'élaboration de valeurs (mérite, utilité sociale) et des manifestations matérielles du succès. L'auteur montre l'imbrication des sphères intime et publique, l'association du confort et du raffinement, l'existence de plusieurs modèles (aristocratique, anglais). Cet article constitue donc une intéressante contribution aux recherches sur le façonnement d'une identité bourgeoise dans la perspective tracée par le colloque Vers un ordre bourgeois?

3 Angelo Celeri étudie l'effort de guerre dans l'Eure. Il faut habiller, équiper, armer les volontaires de 1791 et 1792, puis les requis. L'équipement des premiers se révèle particulièrement difficile, au point que les bataillons organisent leurs propres ateliers. À partir de 1793, les mesures extraordinaires, dont la mise en œuvre est encouragée par les représentants en mission, permettent d'équiper plus rapidement les recrues. Après 
la levée en masse, une économie de guerre est instaurée que l'auteur définit comme « une économie dans laquelle la satisfaction des besoins de l'armée passe avant tout [et] qui, de ce fait, nécessite une large intervention de l'État». Angelo Celeri souligne l'ampleur de l'effort réalisé en 1793-1794 pour équiper et ravitailler les troupes dans un contexte particulièrement difficile.

4 Isabelle Antunes examine la formation, la composition et le fonctionnement des districts normands en 1790. Parmi les élus, les hommes de loi dominent, plus encore chez les procureurs-syndics que chez les administrateurs. Par leurs multiples activités comme par le destin de leurs élus, les districts apparaissent non comme de simples rouages intermédiaires, mais bien comme des instances importantes de la politisation et même comme des creusets pour la "classe politique " qui se dessinera sous le Directoire. Également élus, les procureurs généraux syndics des départements sont chargés de représenter le pouvoir exécutif central et de transmettre les lois. Gaïd Andro étudie ici ceux de Basse-Normandie. Elle s'attache à l'analyse de la crise fédéraliste, en comparant des départements aux trajectoires différentes. Fidèles à leur pragmatisme des années précédentes, ceux de la Manche et de l'Orne font preuve de prudence ; leurs procureurs généraux syndics apparaissent comme des administrateurs soucieux de concilier le local et le national. En revanche, le Calvados est traversé très tôt par de graves tensions: dénoncé par les patriotes, le premier procureur général syndic est lynché en septembre 1792. Son successeur encourage l'adhésion du département à l'insurrection fédéraliste, se comportant donc plutôt comme un représentant. Ainsi, suivant le contexte départemental, le procureur général syndic oscille entre deux figures, relais administratif du pouvoir central ou magistrat départemental élu.

Institutions extraordinaires, les comités de surveillance jouent également un rôle d'interaction entre pouvoir local et pouvoir central. Céline Duclos présente sa recherche sur ceux du district de Montivilliers (Seine-Inférieure). En l'an II, ses 142 communes sont toutes pourvues d'un comité de surveillance, mais certains se révèlent particulièrement actifs, tel celui du Havre. Si tous les comités de surveillance se montrent prudents (seule la moitié des suspects sont arrêtés), certains protègent en fait la communauté locale. En campagne, leurs membres, souvent inexpérimentés, se trouvent confrontés à de nombreux décrets, touchant des domaines variés, et peinent à les saisir. Les comités de surveillance constituent donc d'importantes instances de politisation et leur étude conforte une approche nuancée des politiques de la Terreur.

Enfin, la Constitution de l'an III remanie les institutions locales, notamment en introduisant auprès de chaque département un commissaire central qui, contrairement au procureur général syndic, n'est pas élu. « Æill du Gouvernement » (Bernard Gainot), il «surveille et requiert l'exécution des lois» (art. 191 de la Constitution). Ce commissaire central dirige les commissaires cantonaux, rend compte au gouvernement et réalise des tournées, telles celles qui mènent Alexandre Crochon, premier commissaire de l'Eure, dans les zones attaquées par les royalistes. Dans l'article qu'il consacre à ce personnage, André Goudeau retrouve plusieurs thèmes qui traversent le volume: les engagements et combats politiques, la relation entre pouvoir local et pouvoir national, l'expérience politique et administrative réalisée par des «hommes nouveaux» appelés à former la «classe politique» et le groupe des notables en gestation dès la fin des années 1790. Alexandre Crochon est un ancien avocat. Procureur-syndic de district en 1790, il tente à plusieurs reprises de se faire élire 
député. Au lendemain du 18 fructidor, il est attaqué par les néo-jacobins locaux qui lui reprochent de ne pas parvenir à juguler la montée des violences royalistes. Tandis que le département défend Alexandre Crochon, les néo-jacobins alertent les ministres qui proposent au Directoire sa révocation. Le commissaire conserve pourtant son poste, grâce au soutien de plusieurs députés de l'Eure, anciens fédéralistes comme lui.

$7 \mathrm{Au}$ total, c'est à juste titre que Michel Biard souligne le caractère novateur des recherches ici présentées. 